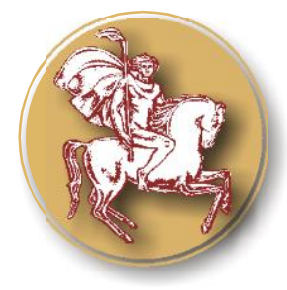

Trakia Journal of Sciences, No 4, pp 365-369, 2021

Copyright (C) 2021 Trakia University

Available online at:

http://www.uni-sz.bg

ISSN 1313-3551 (online)

doi:10.15547/tjs.2021.04.011

\title{
GAMBLERS ANONYMOUS GROUPS DURING THE COVID-19 PANDEMIC - RESEARCH REPORT
}

\author{
B. Hoffmann* \\ Institute of Applied Social Sciences, University of Warsaw, Poland
}

\begin{abstract}
The COVID-19 pandemic, both in Poland and worldwide, has a huge impact on social, demographic and economic processes. The situation we are currently facing is particularly difficult because it is highly unpredictable. Isolation, breaking social relations, fear of infection and any other violation of everyday functioning may pose a serious threat to people maintaining abstinence. Virtual communication proved to be the only alternative to live face-to-face communication during the pandemic. Across the country, meetings of therapy groups have been suspended until further notice. This has led to an unprecedented situation where, out of necessity, GA had to move online. This begs the question of whether this form of contact can replace the traditional face-to-face meetings?
\end{abstract}

Keywords: Gamblers Anonymous, gambling addiction, pandemic, SARS-COV-2 (COVID-19), internet self-help groups, behavioural addictions.

In May 2020, I conducted research (225 persons), on the functioning of self-help Alcoholics Anonymous groups under the conditions of the COVID-19 pandemic. ${ }^{1}$ Such results encouraged me to continue on with my research, moving on to study the example of Gamblers Anonymous, as well as to commit myself to the exchange of further academic and practical knowledge on the subject.

\section{INTRODUCTION}

Over the last few decades, the self-help movement has dynamically grown and increased in power across most of the world. The emergence of the internet allowed new services

${ }^{1}$ The research on was conducted thanks to a microgrant received from IDUB UW (Inicjatywa Doskonałości-Uczelnia Badawcza Uniwersytet Warszawski).

*Correspondence to: Beata Hoffmann, University of Warsaw, Institute of Applied Social Scienceshoffmann.beata@gmail.com,ORCID:00000001-7339-4256 to be created, which can be used without leaving one's home. According to Aza Barak, Meyran Boniel-Nissim and John Suler, online support groups are aimed towards improving personal comfort, sense of control, self-confidence, sense of independence, social interaction, and overall benefitting the emotional sphere of their participants (1). Storm King's research has shown that regular, frequent contact with selfhelp group members can significantly contribute to maintaining abstinence. King also notes that almost all of his respondents see internet groups as complementary to regular, live meetings (2). Małgorzata M. Owczarek's research has also indicated that such groups are an important form of help for people addicted to psychoactive substances, and that they mostly operate through social networks, blogs and internet fora (3).

The COVID-19 pandemic, both in Poland as well as globally, is having enormous effects on social, demographic, and economical processes. The situation we are presently faced is especially 
HOFFMANN B.

difficult, as it is very unpredictable. Months-long isolation, disruption of social relations, fear of infection, and all the other breaches of daily functioning can pose a serious threat to people maintaining abstinence. Virtual communication (via technology) has, during the pandemic, turned out to be the only alternative to live, "face to face" communication. Across the entire country, meetings of therapeutic groups like Alcoholics or Gamblers Anonymous have been suspended until further notice. This resulted in an unprecedented situation where, out of necessity, GA or AA groups had to move online. This leads to a question: can such forms of contact make up for the lack of live, group meetings, and find a use within traditional forms of self-help?

Gambling addiction is a growing problem, which carries with itself a whole slew of negative consequences, ranging from psychological, through physical, to social. As is commonly acknowledged, pathological gambling is not a financial, but an emotional problem, which, like any other addiction mandating treatment, also has financial consequences. For a gambling addict, the first step on the road to recovery is to admit their addiction and make a decision to start therapy. Importantly, such therapy must not only be directed towards the gambling problem itself, but also needs to touch on the entirety of the patients' life, including their leisure time activities, interests, values, and communication with their near and far social circles.

Globally, the first center for treating gambling addiction was created in the United States in the 1970s. The first Polish centers of that type started appearing in the 1990s. The basic forms of work with addicted persons include behavioural therapy, cognitive-behavioural therapy, psychotherapy, and advice (4).

Of special interest here is the Gamblers Anonymous (GA) community, which operates on similar principles to Alcoholics Anonymous. GA members share between themselves their problems and their ways of dealing with them, and give each other support. It is a form of selfhelp that is especially useful for people addicted not only to gambling, but also to alcohol. Those two addictions have a tendency to appear together.
The Gamblers Anonymous community arose in the United States in 1957, due to a chance encounter between two men. They proceeded to start meeting regularly, and noticed that thanks to those meetings, neither of them returned to gambling. They agreed that to prevent a future slip, they had to make a change to their personalities. In order to do so, they took on as their leading principle the same spiritual rules that had helped thousands in their way out of different addictions (like alcoholism). The word "spiritual" here denotes those aspects of the human mind which represent the highest values like compassion, magnanimity, humility, and honesty. The men have also thought it important to carry their message to other serial gamblers. Thanks to that, on the 13th of September, 1957, the first Gamblers Anonymous meeting took place in Los Angeles. Since then, the community has grown, with groups being formed across the globe. In February 1995, the first Polish Gambers Anonymous group was formed, taking on the name Jedynka [Number One]. Since then, the community has spread across the country. Today, GA meetings are held in an increasing number of cities in Poland (5).

\section{RESEARCH GOALS AND METHODS}

This research on the function of Gamblers Anonymous groups under pandemic conditions had exploratory character. It was conducted between the start of February and the start of March 2021. The research was done using a quantitative method, using a special questionnaire. It was conducted online, which, during the pandemic, is the preferred way of reaching respondents. Google forms were used to that end.

Potential respondents were invited using a link on the internet page of the GA community. While the research was not conducted on a random sample, representative for the entire GA community in Poland (as that is impossible under the pandemic conditions), and the research results should not be extrapolated on the entire GA population, it nonetheless provides a useful view into the position of GA groups a year into the COVID-19 pandemic. It also indicates important phenomena in the workings of the community, both currently, as well as in the post-pandemic future. 
HOFFMANN B.

In research conducted between the start of February and the start of March 2021, 27 people participated. They included 24 men and 3 women, between 31 and 49 years in age, with experience in GA meetings usually going between 5 to 10 years (a full third of respondents). Notably, a significant portion of respondents, when asking about their subjective numbers of finished steps in the Twelve Steps Programme, indicated 12 (9 instances). It should also be noted that over a half of respondents refused to answer this question.

\section{GA meetings before the pandemic}

All respondents declared that before the 15th of March, 2020, their GA group meetings used to be held at least once a week, and they themselves participated in one or two of such groups. 18 respondents declared attending groups once or twice a week, while 6 indicated a bi-weekly attendance. The majority (21) declared that they were attending groups beyond their own. No one noted negative emotions pertaining to group attendance. Almost all respondents (26) instead noted very positive or positive emotions. Before March, 2020, the majority of research participants (15) have not participated in professional therapy, and those who did (11) attended such therapy up to twice a week (4) or once every week or every two weeks (3).

Respondents who before the pandemic used to meet with a therapist or a specialist reported positive emotions with that regard (6), or overwhelmingly positive (2). The majority of respondents never had a sponsor, or were not meeting with one before the pandemic ( 9 and 7 cases). Such meetings were reported by 10 respondents.

\section{What has changed in the pandemic?}

According to all respondents (27), the pandemic caused changes in the functioning of the GA group meetings, their frequency and format. The changes mostly had to do with the new form of group meetings. They were moved online and started to be held either fully remotely (20) or in a mixed form (16). For 10 people, meetings ceased to be held altogether. One person reported that their group fell apart earlier. Eleven people whose groups moved to the internet did not remember when exactly that happened, but 9 reported an immediate move to the remote sphere
- the first GA meeting online was held during March 2020. Seven respondents had to wait for such meetings until somewhere between April and June.

The frequency of GA meetings increased rapidly. 17 respondents reported that they were being held daily, the remaining 6 indicated at least once or twice a week. For 2 respondents, their groups would meet 5 or 6 times a week. Only one person declared meetings once a month, and only one was not able to determine the frequency of their meetings.

Only one person attended their group meetings daily. A slight majority of people who experienced the move of their GA groups online participated in them 1-2 a week, or 3-4 times a week ( 7 and 7 in both cases). 5 people reported a bi-weekly attendance. Once a month was reported by 1person attendance of less than once a month by 2 . Four respondents declared a total lack of attendance in such meetings.

This increase in activity was tied with maintaining high levels of satisfaction in GA group meetings. Attendees of meetings held online declared positive (10) and overwhelmingly positive (5) emotions related to them. Neutral emotions were reported by 5 respondents, and 4 had no opinion.

Online participation was highly valued by respondents, primarily because such a form allowed them to hear from new and interesting people living far away (15), and from such persons that had not previously participated in live meetings (13). Important, positively appraised factors were also: the ability to actively participate (12) and easier scheduling. Other positive aspects were indicated by fewer than 4 persons each.

Worse overall feeling was noted to be the main flaw in remote GA meetings. The majority of respondents (16) participating in such groups reported feeling better during live meetings. The fact that online meetings do not encourage authentic engagement (10) was also noted, as well as the fact that some group members stopped attending online meetings altogether (8). Four people reported finding no significant flaws in online GA meetings. According to one person, online GA meetings are not comparable to live 
HOFFMANN B.

ones and should only serve as a stop-gap measure for the pandemic. One person noted no participation in online meetings.

In cases of traditional, live GA meetings, respondents more frequently selected more advantages when compared to remote meetings held over the internet during the pandemic. In almost all cases, the majority appreciated each advantage of traditional, live meetings, which were indicated by fewer respondents each in the context of online meetings. The biggest decrease (the difference between indications for the prepandemic and pandemic situation) was in the ability to acquire a realistic self-image (from 17 to 3 ), in friendships within the group (18 to 5), building self-respect (15 to 3 ) and learning proper attitudes and behaviours (17 to 5). To a lesser degree, a decrease was also noted in the direct contact with other gamblers and the ability to acquire support from them (10 fewer selections, from 17 to 7), and in honesty of other participants (15 to 5 selections). The smallest decrease was noted in factors such as the possibility of acquiring acceptance from others (from 11 to 7 selections) and the ability to live through struggles together (from 14 to 10). No selections remained stable across both forms of GA meetings. The shift to online meetings was generally appraised negatively, and the differences are in the degree to which particular aspects were affected.

The idea of replacing traditional live GA meetings with online ones found no support among the respondents. Not one of them noted a preference for online only future of GA meetings. The majority reported the desire to participate mostly in traditional, direct meetings, with the caveat that the online format could sometimes serve a complementary function. The reverse traditional meetings as complementary to remote ones - was supported by only one respondent. Eleven declared preference for live-only group meetings.

Use of specialist therapy decreased slightly. This form of help was used by 11 respondents, and after the 15th of March, 2020, only 9. Those who continued specialist/therapist support tended to meet with them under a more rigid schedule once or twice a week, or once a month.
Organizational factors (such as easier scheduling) dominated among the reported advantages of the new, remote form of contact with therapists, alongside individualization of meetings with the therapist (indicated by 2 respondents). The majority of research participants saw no negative phenomena associated with an individual, online meetings (5 out of 9), while most reported downsides had to do with perceived artificiality of such a form of meetings.

The size of the group of people that used to contact their sponsors before the pandemic remained roughly unchanged. People who before the pandemic had a sponsor tended to remain in contact with them after the 15th of March. People without a sponsor before the 15th of March did not find one in the pandemic conditions. Respondents contacted their sponsors primarily via phone (8) or internet (5), or sometimes in personal meetings (6).

\section{How did the pandemic affect the respondents' lives?}

26 out of 27 respondents declared holding to their abstinence in the pandemic. Most of them have been in abstinence for 1 to 5 years or from 6 to 10 years (12 and 9). 4 respondents reported more than 11 years of abstinence, and one respondent less than one year.

The pandemic had a noticeable effect on the perception of life quality by the respondents. Two respondents graded their life between 3 and 5 (on a scale going up to 10). The lowest pre-pandemic grade - 2, noted only once back then - lost its lowest status during the pandemic. 6 and 7 grades gained one selection each, 9 gained two, and the highest possible grade of 10 was selected by one person. The biggest surprise was the drop from the grade 8 , from eight selections to only one. People grading their life at 8 before the pandemic have changed their mind the most, usually to the negative.

\section{CONCLUSIONS}

- The COVID-19 pandemic affected practically every respondent. GA group meetings changed their format, especially the form, frequency, and cooperation with therapists and sponsors.

- Online meetings increased in frequency compared to live ones. People who did not 
resign from attending altogether, the intensity of their participation in meetings increased.

- The level of satisfaction with online meetings decreased. The biggest flaws of such a form are seen in the overall feeling - many participants feel better live - and in the fact that some previous attendees stopped showing up in online meetings.

- Respondents reported feeling that online meetings provide them with fewer advantages than traditional meetings do. This affected interpersonal contact between gamblers the most.

- Respondents also noted positive aspects of online meetings: the opportunity to meet new people living in distant areas and easier scheduling and time savings.

- Therapeutic relations were not particularly affected by the pandemic.

- Almost all respondents held to abstinence during the pandemic. Those who broke it were people with short (usually a year, five years at most) experience with abstinence.

- After the pandemic is over, respondents want to return to the traditional form of GA meetings. However, due to their certain advantages, online meetings may serve a useful complementary function. It should not be expected, however, that they will replace live ones.
HOFFMANN B.

While internet groups are a widespread form of giving support, and such aspects of cyberspace as anonymity and widespread access facilitate greater openness of their members compared to traditional forms of communication (6), this research showed that the traditional form of meetings is vastly preferable. Online meetings can only serve a complementary function.

\section{REFERENCES}

1. Barak A., Boniel-Nissim M., Suler J., Fostering empowerment in online support groups. Computers in Human Behavior, 24, 2008, p. 1867-1883.

2. King S. A., Analysis of electronic support groups for recovering addicts. Interpersonal. Computing and Technology: An Electronic Journal for the 21st Century, 2(3), 1994, p. 47-56.

3. Owczarek M.M., Internetowe grupy wsparcia jako forma pomocy dla osób uzależnionych od substancji psychoaktywnych [Internet support groups as a form of help for substance abuse]. Warszawa: Wydział Stosowanych Nauk Społecznych i Resocjalizacji. Uniwersytet Warszawski, 2018. Unpublished doctoral dissertation

4. Niewiadomska I., Brzezińska M., Lelonek B., Hazard [Gambling]. Lublin, KUL, 2005.

5. http://www.anonimowihazardzisci.org/histori a-ah.html; access: 23.03.2021

6. Owczarek M., op. cit. 